\title{
PUBLIC AND PRIVATE HEALTH CARE SERVICES IN THE OPINION OF PHYSICIANS IN POLAND
}

\section{WOJCIECH STEFAN ZGLICZYŃSKI ${ }^{1}$, MATEUSZ JANKOWSKI ${ }^{1}$, OLGA ROSTKOWSKA ${ }^{2}$, JANUSZ SYTNIK-CZETWERTYŃSKI ${ }^{1}$, DANIEL ŚLIŻ ${ }^{1}$, ALEKSANDRA KARCZEMNA ${ }^{3}$, and JAROSŁAW PINKAS ${ }^{1}$}

${ }^{1}$ Centre of Postgraduate Medical Education, Warsaw, Poland

School of Public Health

${ }^{2}$ Medical University of Warsaw, Warsaw, Poland

Department of Transplantation Medicine, Nephrology and Internal Diseases

${ }^{3}$ Warsaw University of Life Sciences, Warsaw, Poland

Department of Dietetics, Faculty of Human Nutrition

\begin{abstract}
Objectives: Health care services in Poland are delivered by public and private providers. The aims of this study were to assess the attitudes towards private and public health care services in Poland and to identify differences between them, in the opinion of physicians. Material and Methods: A questionnaire-based survey was carried out among physicians attending mandatory courses delivered at the School of Public Health, the Centre of Postgraduate Medical Education in Warsaw, Poland. The questionnaire included 29 questions concerning private and public health care services. Results: Completed questionnaires were obtained from 502 physicians (67.7\% females), aged $42.1 \pm 10.8$ years, with a response rate of $77.2 \%$. In the opinion of the surveyed doctors, the major advantages of private health care units, in comparison with public ones, are short waiting times for an appointment $(88.2 \%)$, an efficient on-site service $(78.6 \%)$ and convenient appointment times $(75.7 \%)$. The respondents gave high scores to items such as relations with patients $(\mathrm{p}<0.001)$, superiors $(\mathrm{p}<0.001)$ and colleagues $(\mathrm{p}=0.03)$ when working in private, rather than public, institutions. In the opinion of physicians, public health care institutions guarantee better employment conditions $(44.4 \%$ vs. $13 \%$; $p<0.001)$ and security $(29.1 \%$ vs. $11.1 \% ; p<0.001)$ than private ones. The respondents did not observe any differences $(p>0.05)$ between public and private facilities in terms of the involvement of medical staff and infrastructure. There were significant differences $(p<0.001)$ in the perception of working conditions in public and private health care institutions depending on the medical education level and the place of primary employment. Conclusions: Among physicians in Poland, private medical institutions are perceived as better organized and granting faster as well as more comprehensive access to health care services when compared to public ones. Closing the gaps between working conditions in public and private units could encourage physicians to practice in the public health care sector. Int J Occup Med Environ Health. 2020;33(2):195-214
\end{abstract}

Key words:

physicians, health care, health care facilities, health care workers, health system organization, private and public

\section{INTRODUCTION}

According to the Constitution of the Republic of Poland (Article 68), everyone has the right to have access to health care [1]. To ensure access to health care services, public authorities have organized a publicly funded health care system [1]. Residents of Poland may receive free medi- cal assistance if they have their health insurance covered within the National Health Fund (Narodowy Fundusz Zdrowia - NFZ) [1-4]. The insurance is obligatory for all employees [2]. Moreover, the government is obliged to provide free health care services to young children, pregnant women, disabled people and the elderly [1].

Received: May 15, 2019. Accepted: December 12, 2019.

Corresponding author: Jarosław Pinkas, Centre of Postgraduate Medical Education, School of Public Health, Kleczewska 61/63, 01-826 Warsaw, Poland (e-mail: jaroslaw.pinkas@cmkp.edu.pl). 
In addition to public health care institutions, there is a whole range of private medical facilities [5]. A holder of the insurance within the NFZ may also use the services of private medical facilities (without incurring any additional costs) if that practice has signed a contract with the NFZ [2]. The use of health care services in private facilities without a contract with the NFZ, as well as by uninsured persons in both types of institutions, is fully paid. However, increasingly popular are also private health insurances which provide their holders with access to selected private medical facilities [6,7]. In 2016, 1.86 million Poles had an additional private health insurance [6]. In 2 years, the percentage of people with private health insurance increased by almost $40 \%$, reaching 2.6 million Poles in 2018 [7].

The use of health care services in Poland, along with measurements of patient satisfaction, is regularly monitored by research companies, such as the Public Opinion Research Center (Centrum Badania Opinii Społecznej-CBOS) [8,9]. According to the CBOS report "Health care benefits and insurance" published in 2016, 84\% of Poles declared using health care services at least once in the last 6 months [8]. The dominant group (40\%) of the respondents declared using both public and private health care services, $37 \%$ were treated only within services financed by the NFZ, and $7 \%$ used private medical services exclusively [8].

The next edition of the report, published in 2018, showed that the percentage of people who had used health care services at least once in the previous half a year increased to $88 \%$ [9]. An increase in the number of people attending private medical facilities was observed [9]. Almost half of the respondents (48\%) using health care services in 2018 decided to use the services of both public and private health care institutions [9]. The percentage of Poles attending only private medical facilities increased to $9 \%$ [9]. Among private health care services, the most often used are specialist visits and dental care [8,9]. The main reason behind using private medical facilities is a short waiting time for a visit in a private facility when compared to public health care units $[8,9]$.

The health care system in Poland is constantly changing $[3,10]$. The reform of this system requires a joint commitment of decision-makers, patients and health care professionals [11]. Numerous studies assess patients' opinions on different aspects of health care services provided in public and private medical facilities $[8,9,12]$. However, there is no data on the attitudes towards the public and private sector in Poland, from the point of view of medical staff, including physicians. A regular monitoring of physicians' opinions about health care services quality and working conditions in private and public institutions is necessary to address the needs of medical staff during the development of health care reforms $[10,11]$. The aims of this study were to:

- assess individual beliefs and attitudes of physicians towards private and public health care services in Poland; - identify differences between public and private health care institutions in the opinion of physicians practicing in Poland.

\section{MATERIAL AND METHODS \\ Participants}

A paper-based survey was conducted in January-June 2016. In Poland, each physician undertaking specialty training is required to attend a public health course. The authors approached physicians attending the training courses delivered at the School of Public Health, the Centre of Postgraduate Medical Education (Warsaw, Poland), in the first half of 2016 (15 different courses). All 650 physicians attending these courses were eligible to take part in the survey. The participation in the course is compulsory for each of 16200 physicians undergoing specialty training in Poland. The participants represented different regions and health care institutions from all over the country. In 2018, the questionnaire-based survey was conducted again in a group of 120 physicians. 


\section{Questionnaire}

The research tool was an original questionnaire developed for the purpose of this study. The questionnaire included 29 questions regarding private and public health care services. Questions also probed background information: age, sex, level of training, years of professional experience, as well as practice characteristics (Table 1).

Table 1. Characteristics of 502 Polish physicians participating in the study on attitudes towards private and public health care services in Poland and differences between them, in the opinion of physicians, performed in January-June 2016

\begin{tabular}{|c|c|}
\hline Variable & $\begin{array}{c}\text { Respondents } \\
(\mathrm{N}=502)\end{array}$ \\
\hline \multicolumn{2}{|l|}{ Age [years] } \\
\hline $\mathrm{M} \pm \mathrm{SD}$ & $42.1 \pm 10.8$ \\
\hline $\min .-\max$ & $28-72$ \\
\hline \multicolumn{2}{|l|}{ Gender $[\mathrm{n}(\%)]$} \\
\hline male & $162(32.3)$ \\
\hline female & $340(67.7)$ \\
\hline \multicolumn{2}{|l|}{ Medical education level $[\mathrm{n}(\%)]$} \\
\hline residency (physician-in-training) & $249(49.6)$ \\
\hline specialist & $253(50.4)$ \\
\hline \multicolumn{2}{|l|}{ Professional experience [years] } \\
\hline $\mathrm{M} \pm \mathrm{SD}$ & $13.9 \pm 10.9$ \\
\hline $\min .-\max$ & $1-45$ \\
\hline \multicolumn{2}{|l|}{ Place of primary employment (practice type) [n (\%)] } \\
\hline hospital & $268(53.4)$ \\
\hline ambulatory care & $234(46.6)$ \\
\hline \multicolumn{2}{|l|}{ Type of primary employment $[\mathrm{n}(\%)]$} \\
\hline public institution & $286(57.0)$ \\
\hline private institution & $216(43.0)$ \\
\hline \multicolumn{2}{|l|}{ Number of places of employment [n (\%)] } \\
\hline 1 & $193(38.4)$ \\
\hline 2 & $174(34.7)$ \\
\hline 3 & $83(16.5)$ \\
\hline$\geq 4$ & $52(10.4)$ \\
\hline \multicolumn{2}{|l|}{ Average weekly working time in total $[\mathrm{n}(\%)]$} \\
\hline$\leq 40 \mathrm{~h}$ & $161(32.1)$ \\
\hline $41-60 \mathrm{~h}$ & $189(37.6)$ \\
\hline $61-80 \mathrm{~h}$ & $94(18.7)$ \\
\hline$>80 \mathrm{~h}$ & $26(5.2)$ \\
\hline do not know/irregular working time & $32(6.4)$ \\
\hline
\end{tabular}


Questions regarding individual beliefs and attitudes towards public and private health care services were divided into 2 parts.

In the first part of the survey, the following inquiry was posed: "What, in your opinion, distinguishes public and private health care services, what is common for both types of health care providers, and what is not associated with any of them?". The question covered 10 items regarding individual beliefs and attitudes towards public and private health care services: waiting time, efficiency and quality of provided services, staff attitude towards patients, staff competence, infrastructure and conditions, as presented in Table 2. For each of the aspects, one of the following had to be indicated: "private," "public," "both," "none" or "hard to say."

In the second part of the questionnaire, the following instruction was formulated: "Regardless of whether you have some work experience in public and/or private health care institutions, please assess the following aspects of work." This question covered 16 items concerning differences between working conditions in public and private health care institutions (Table 3). The range of attitudes was measured with a 6-point school grade scale: $1=$ "unsatisfactory," 2 = "passing," 3 = "satisfactory," 4 = "good," 5 = "very good," and 6 = "excellent." Both public and private health care units were scored separately for each item.

The participants were assigned to either a residency group (physicians-in-training, residents) or a specialist group (with at least 1 specialty completed). Based on the selfdeclared place of primary employment (practice type), the subjects were assigned to a hospital or ambulatory care group. Depending on the type of primary employment, the participants were classified as a public or private sector group.

Repeatability of the questionnaire was assessed in a pilot study where 12 physicians completed the identical questionnaire twice, 7 days apart. Questionnaires as well as

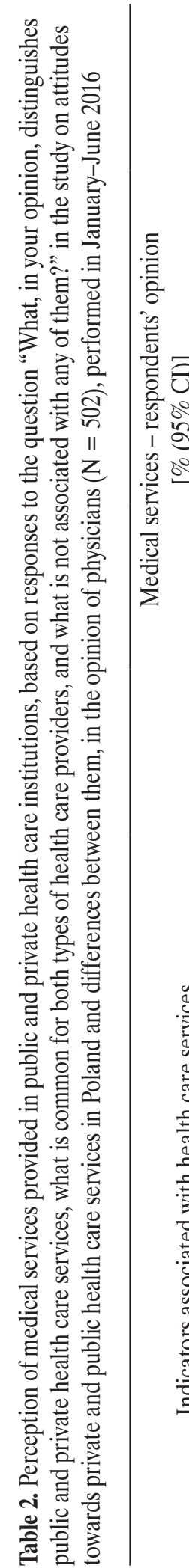

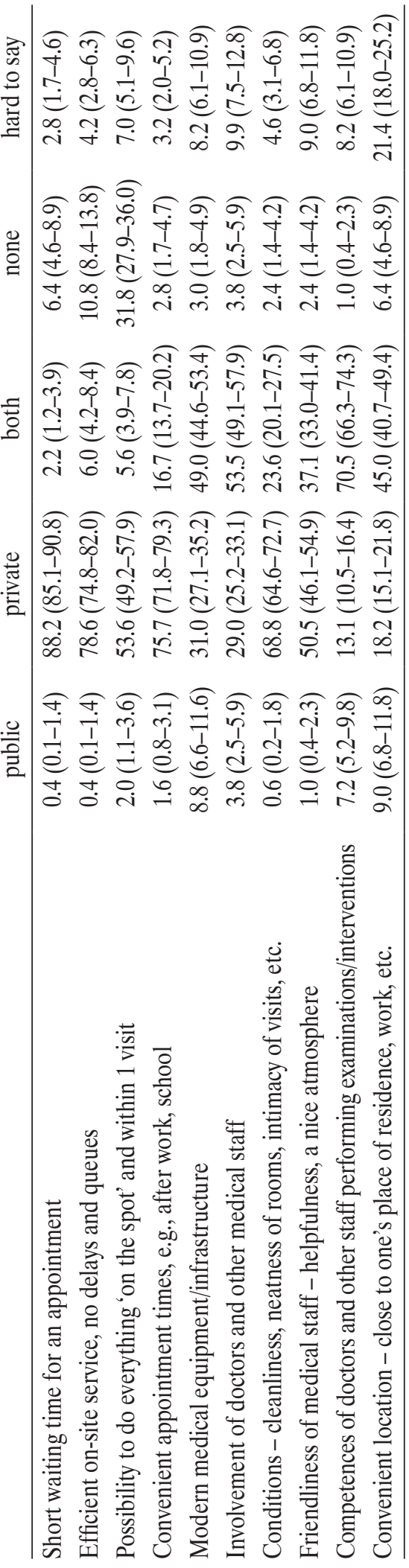




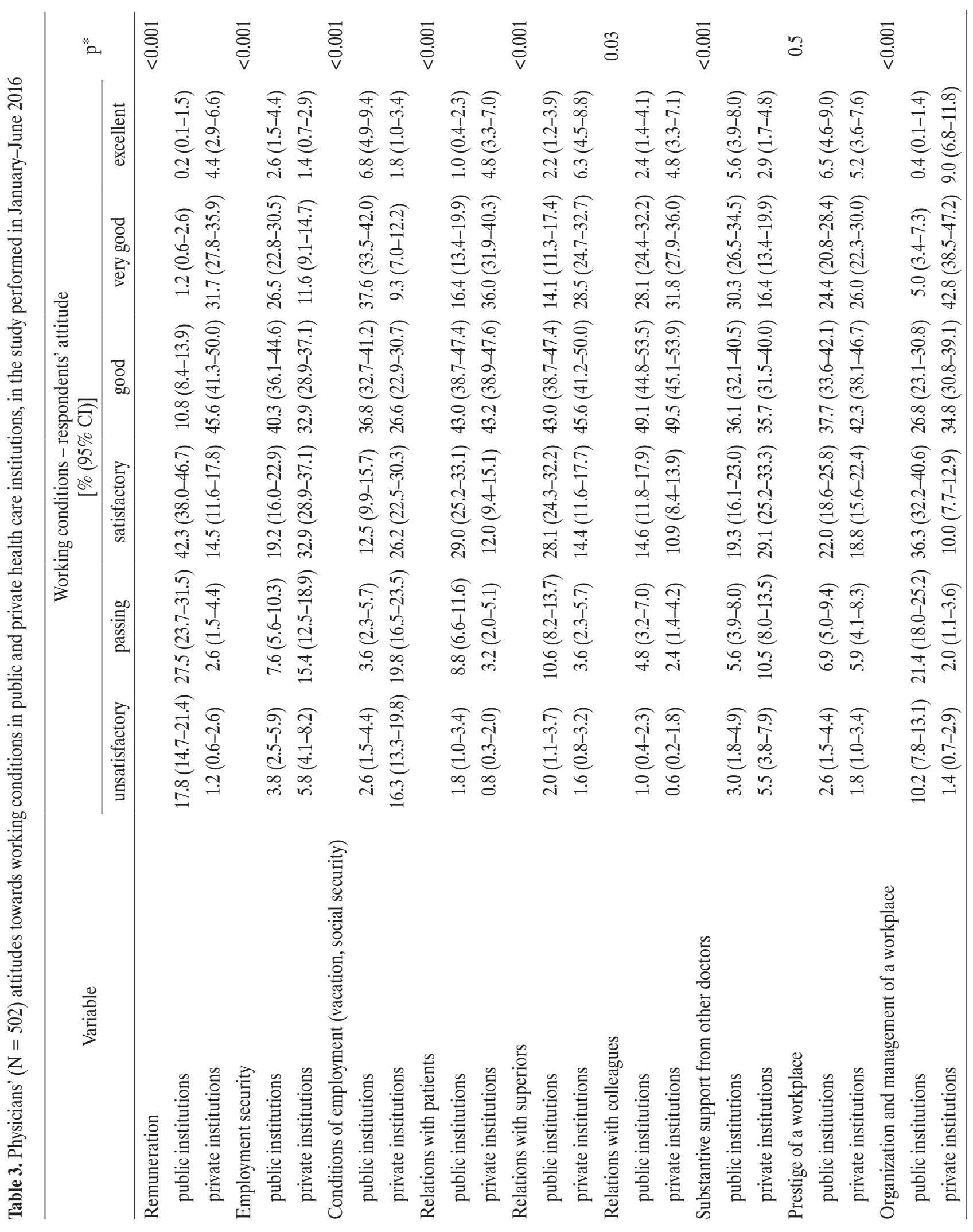




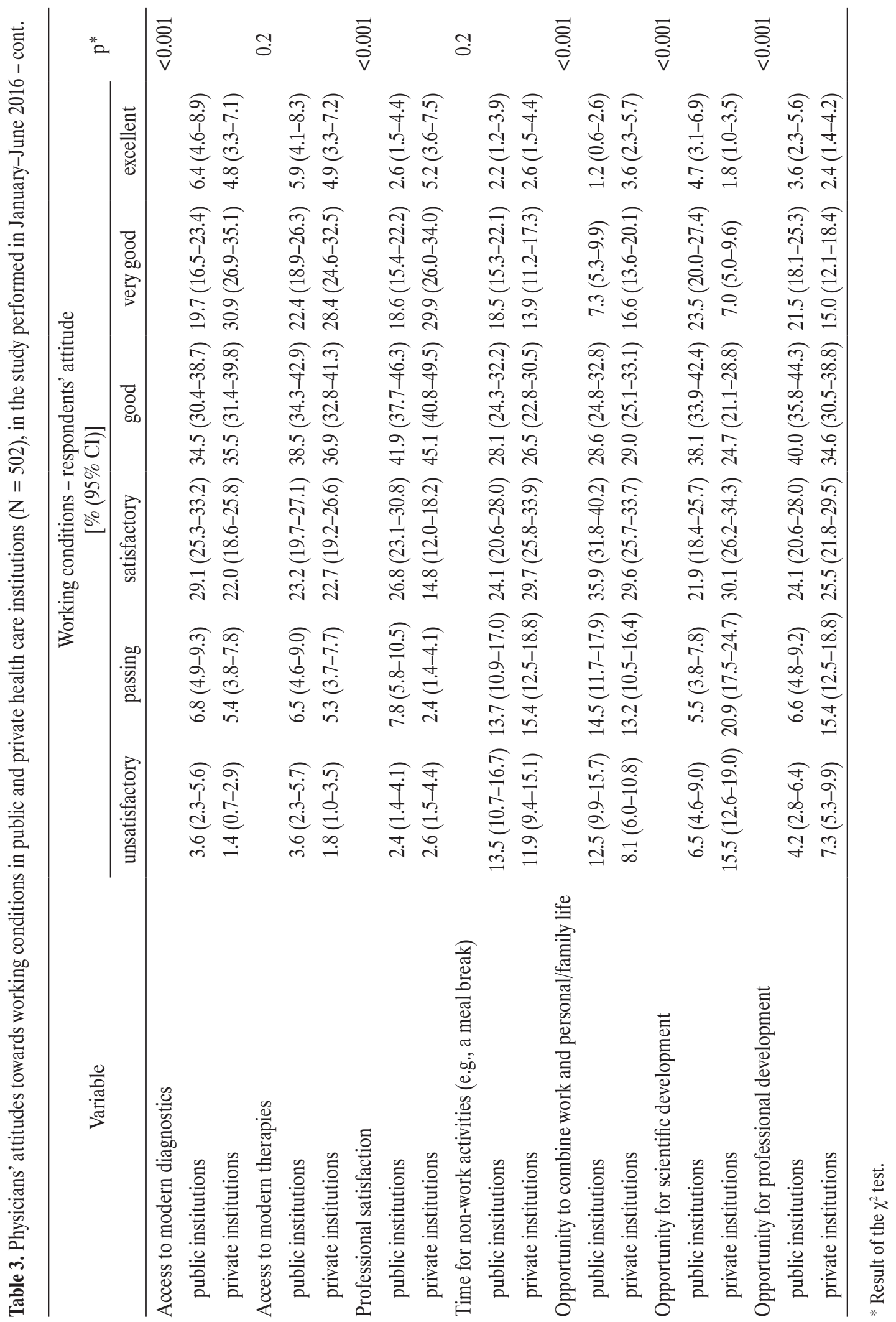


the form of distribution were identical. Kappa coefficients for the critical questions ranged $0.88-0.96$.

The questionnaire was delivered to the participants by a member of the research team. Participation in the study was voluntary and anonymous. Informed consent was obtained from all individual physicians involved in the study. All procedures performed in studies involving human participants were in accordance with the ethical standards of the institutional and/or national research committee, and with the Declaration of Helsinki of 1964 and its subsequent amendments, or with comparable ethical standards.

\section{Statistical analysis}

The data was analyzed with Statistica 12 Software (TIBCO Software Inc., Palo Alto, CA, USA). The normality of distributions of continuous variables was assessed by the Shapiro-Wilk test. The distribution of categorical variables was shown by frequencies and proportions along with $95 \%$ confidence intervals. Chi-square test was used to compare categorical variables. Statistical inference was based on the criterion of $p<0.05$.

\section{RESULTS}

\section{Physicians' characteristics}

Data was obtained from 502 physicians ( $67.7 \%$ females), with a response rate of $77.2 \%$. The average age of the respondents was $42.1 \pm 10.8$ years, with no age differences between males and females ( $p>0.05)$. Among the participants, $49.6 \%$ were physicians-in-training, and $50.4 \%$ were specialists. More than half of the respondents $(53.4 \%)$ declared hospital as a place of primary employment. Among the participants, $57.0 \%$ were primarily employed in a public medical facility. Almost two-thirds of the respondents $(61.6 \%)$ were employed in $>1$ facility. Most of the physicians $(67.9 \%)$ worked $>40 \mathrm{~h} /$ week. Specialists $(43 \%)$, physicians primarily employed in ambulatory care (44\%) and those who worked primarily in private institutions (47.2\%) more often declared only 1 place of employment, com- pared to residents $(33.7 \% ; \mathrm{p}=0.03)$, physicians employed in hospitals $(33.6 \% ; \mathrm{p}=0.04)$ or those working in public institutions $(31.8 \% ; \mathrm{p}=0.001)$. Detailed respondents' characteristics are presented in Table 1.

\section{Attitudes towards medical services provided by public and private health care institutions}

A short waiting time for an appointment was the major advantage of private health care services, declared by $88.2 \%$ of the respondents. Among the respondents, $78.6 \%$ admitted that private health care services are characterized by an efficient on-site service, and $75.7 \%$ pointed to convenient appointment times. More than half of the respondents indicated private health care services as more comfortable $(68.8 \%)$, better organized $(53.6 \%)$ and provided by more friendly staff $(50.5 \%)$, compared to public medical services (Table 2). In the opinion of the participants, both public and private health care services employ competent medical staff $(70.5 \%)$. Most of the respondents did not observe differences between public and private facilities in terms of the involvement of medical staff $(53.5 \%)$, infrastructure (49\%) and location of the medical facility (45\%) (Table 2).

Among the participants, 57\% declared that health care services covered by the NFZ should be provided by institutions offering high-quality services, regardless of the ownership structure. One-tenth (10.8\%) of the physicians surveyed pointed out that publicly funded medical services should be provided only in public institutions, 5.2\% indicated private ones, and $27 \%$ declared that the ownership structure did not influence the quality of health care services.

Specialists, compared to physicians-in-training, more often indicated private entities as places with competent (17.1\% vs. $9.2 \%$; $p=0.01$ ) and involved (36.6\% vs. $21.4 \%$; $\mathrm{p}=0.006)$ staff. Residents appreciated a convenient location of private entities more often than specialists $(20.2 \%$ vs. $16.3 \% ; \mathrm{p}=0.02$ ). Physicians who worked in private 
entities, when compared to those employed in public entities, more often declared that competent ( $20.0 \%$ vs. $8.0 \%$; $\mathrm{p}=0.001)$ and involved (37.3\% vs. $22.8 \% ; \mathrm{p}=0.01)$ medical staff are mostly employed in private entities. The same opinions were shared by physicians employed in ambulatory care compared to those working in hospitals: $18.8 \%$ vs. $8.2 \%(p=0.001)$ and $35.8 \%$ vs. $23.1 \%(p=0.01)$, respectively.

\section{Attitudes and beliefs about working conditions in public and private health care institutions}

In the opinion of $44.4 \%$ of the participants, public health care institutions guarantee very good or excellent conditions of employment, and $29.1 \%$ appreciate employment security in the public sector (Table 3). The same aspect of working conditions was among those rated the lowest in private health care entities ( $p<0.001$ ). Only $13 \%$ of the respondents rated employment security in private entities as very good or excellent, and $11.1 \%$ gave high scores to the conditions of employment in private health care entities. Remuneration was rated higher in private entities than in public ones $(\mathrm{p}<0.001)$. More than half of the respondents $(51.8 \%)$ evaluated the organization and management of a workplace in private entities as very good or excellent. In contrast, only $5.4 \%$ of the respondents considered the organization and management of public health care entities as very good or excellent $(\mathrm{p}<0.001)$. The respondents rated high their relations with patients $(\mathrm{p}<0.001)$, superiors $(\mathrm{p}<0.001)$ and colleagues $(p=0.03)$ when working in private, rather than public, institutions.

There were no significant differences in the attitudes towards the prestige of a workplace $(p=0.5)$ and the time for non-work activities $(\mathrm{p}=0.2)$ in public and private entities. Access to modern therapies was perceived as comparable in both types of entities ( $p=0.2)$; however, the private ones were considered as providing better access to modern diagnostics $(p<0.001)$. Opportunities for scientific or professional development were highly rated in relation to the public, rather than private, entities $(\mathrm{p}<0.001)$. Nevertheless, private entities were perceived as places providing higher $(\mathrm{p}<0.001)$ professional satisfaction and more opportunities to combine work and personal life. Differences in the attitudes towards working conditions in public and private entities are presented in Table 3 .

Physicians' attitudes towards working conditions in public and private health care institutions, depending on the medical education level, the place and type of primary employment were also assessed (Tables 4 and 5). There were statistically significant differences $(p<0.05)$ in the opinions about salary, the prestige of a workplace, professional satisfaction, substantive support in the workplace and work schedule in public health care entities between physicians-in-training and specialists, doctors primarily employed in public or private institutions, as well as those who mostly practice in hospitals, compared to those who practice in ambulatory care (Table 4). The practice type and the place of primarily employment also had an impact $(\mathrm{p}<0.05)$ on the physicians' attitudes towards access to modern diagnostics and therapies, as well as the opportunity for professional or scientific development in public health care entities (Table 4).

Opinions about working conditions in private facilities were less varied between the subgroups of doctors (Table 5). The only difference between the working conditions in private health care entities, in the opinion of physicians-in-training and specialists, were opportunities for professional development $(\mathrm{p}=0.04)$. The practice type (hospital or ambulatory care) and the place of primary employment (a public or private entity) had a significant impact $(\mathrm{p}<0.05)$ on attitudes towards salary, access to modern therapies, prestige and the organization of a workplace, and the opportunity for professional or scientific development in private health care entities (Table 5). 


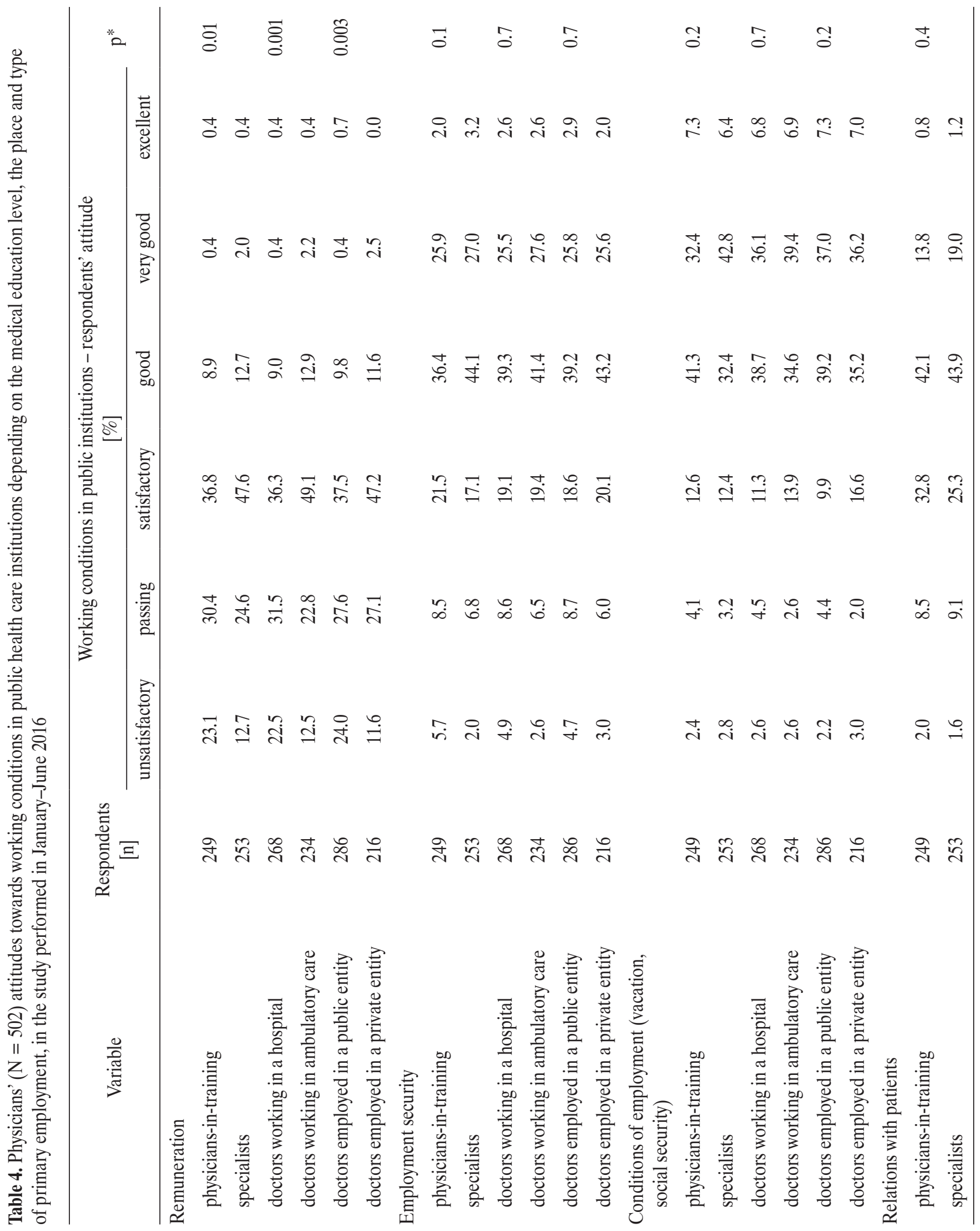




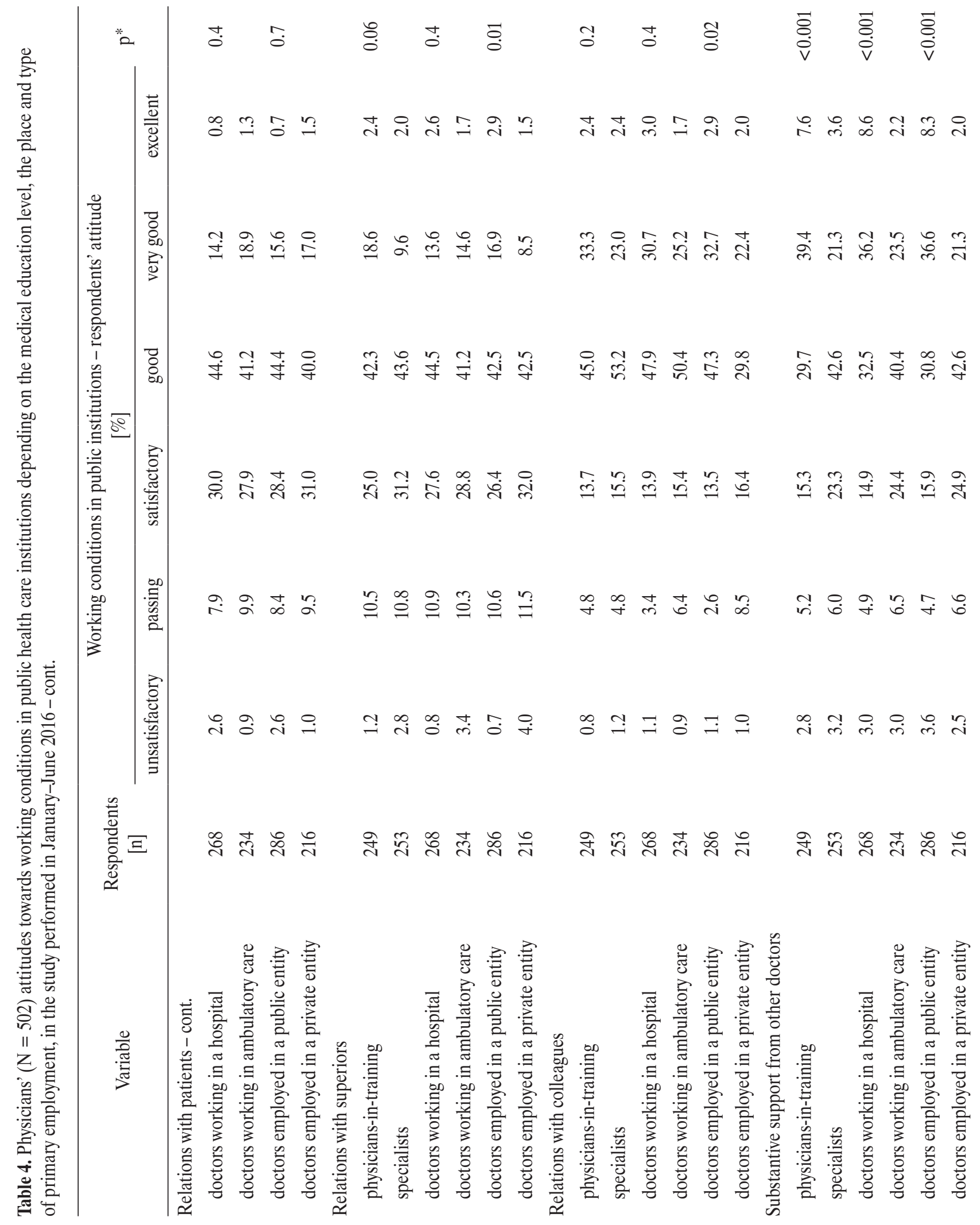




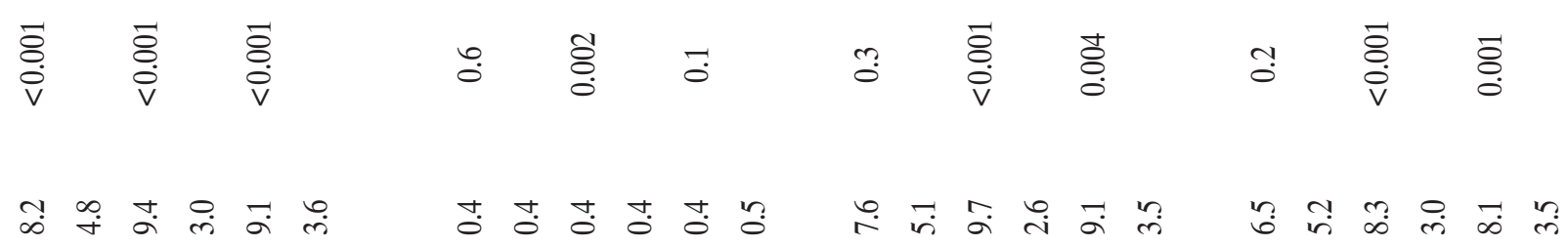

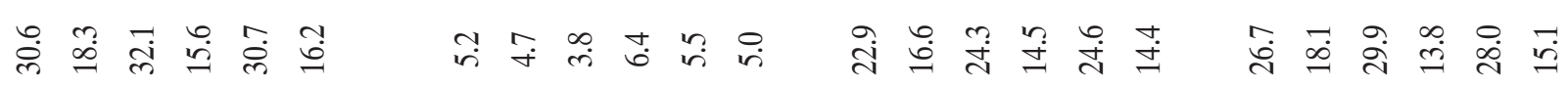

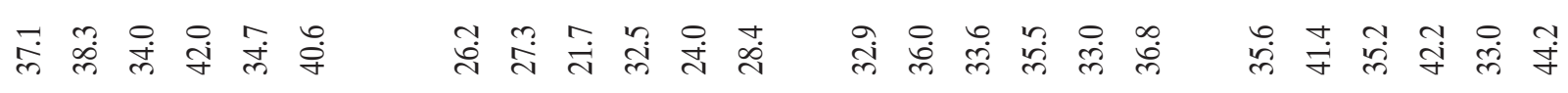

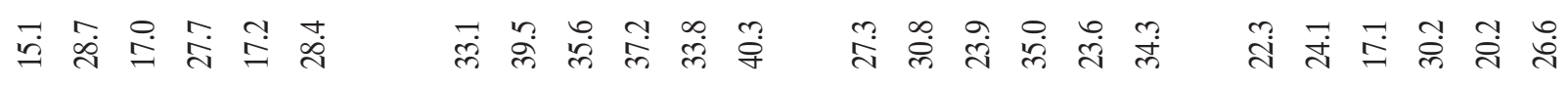

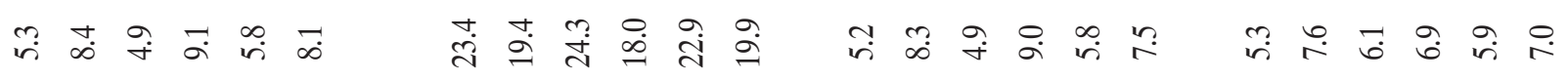

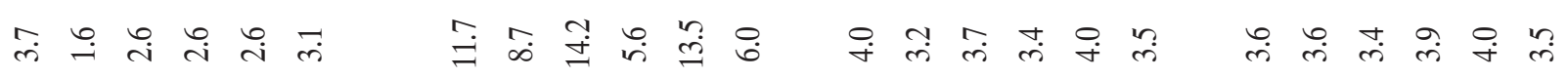

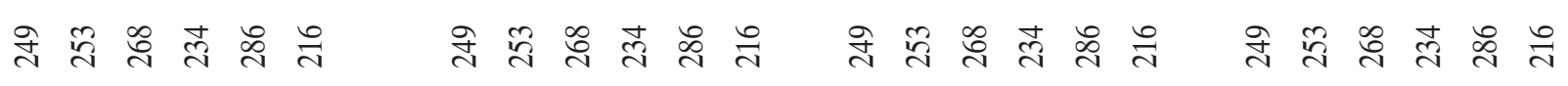

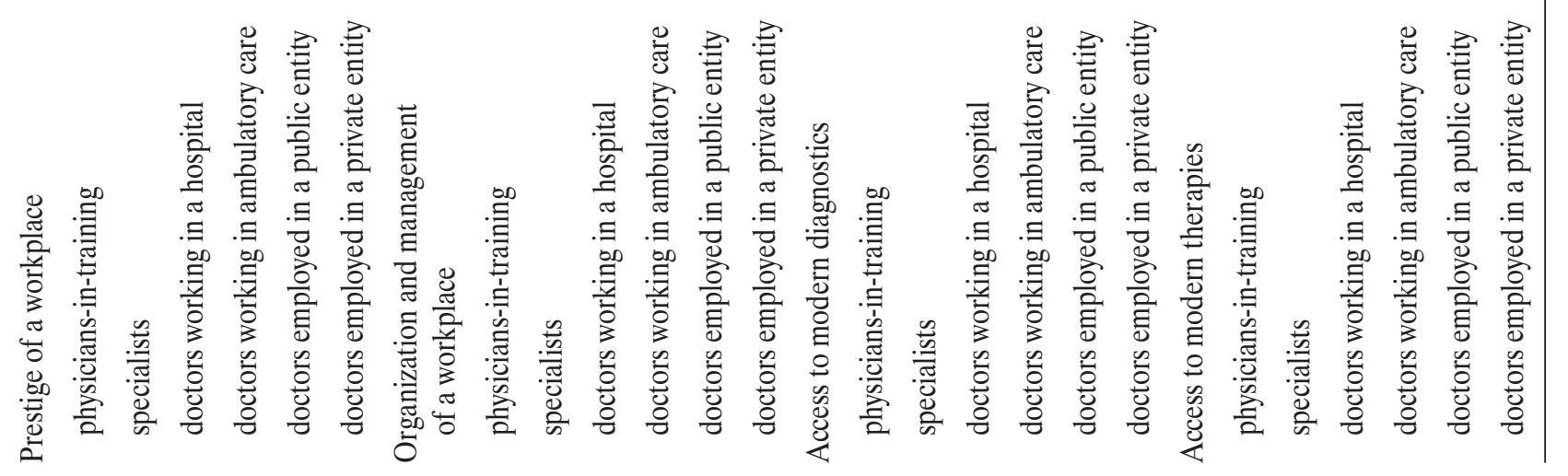




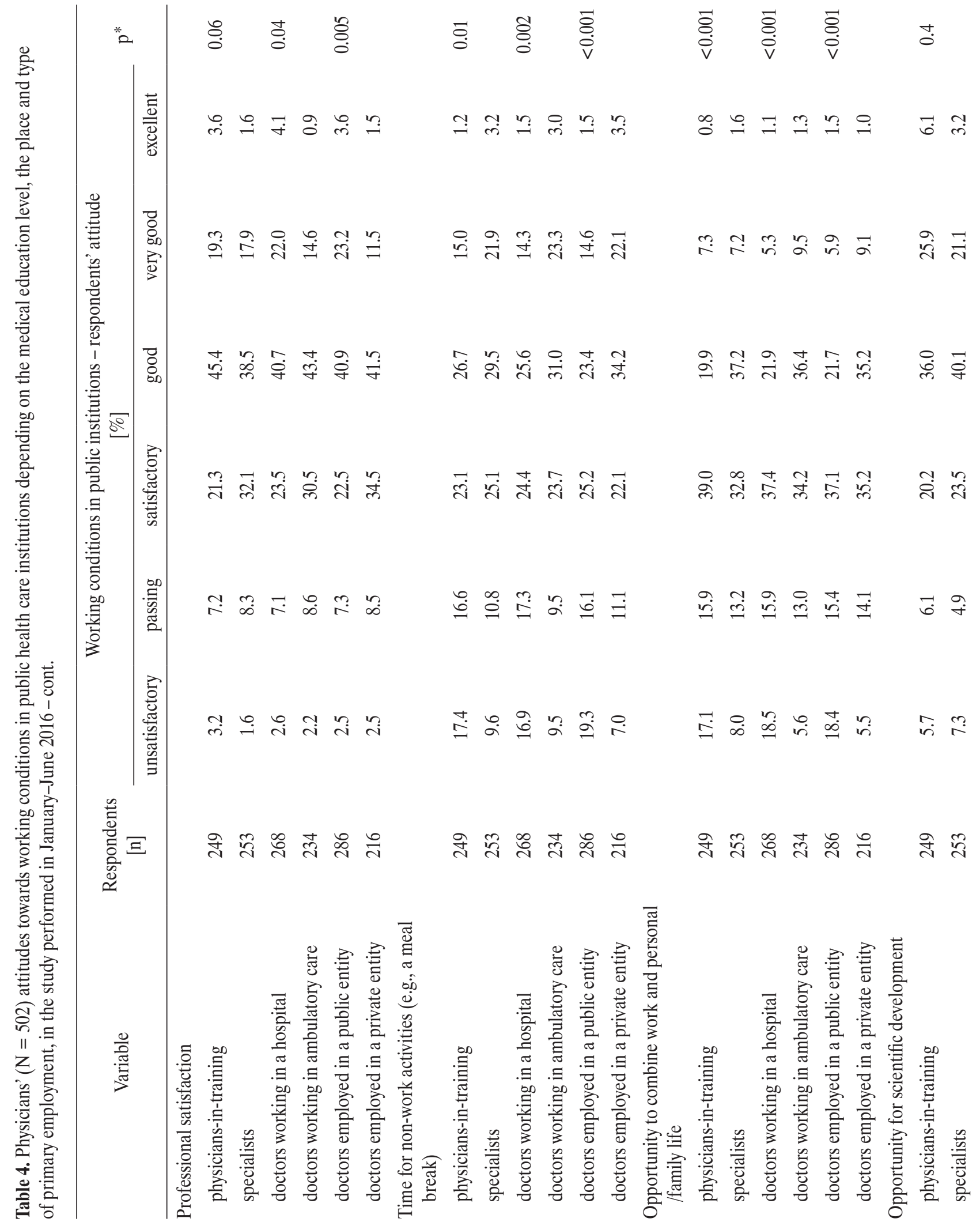


형

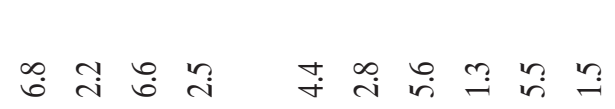

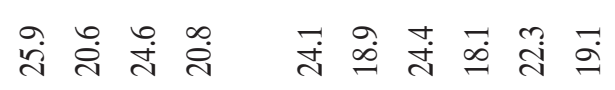

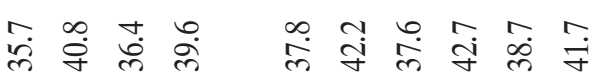

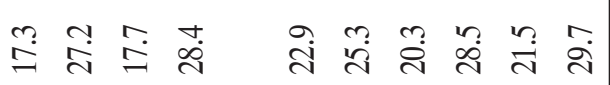

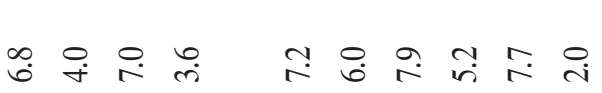

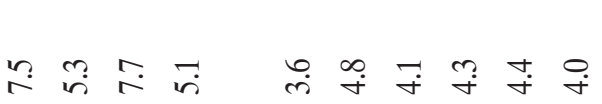

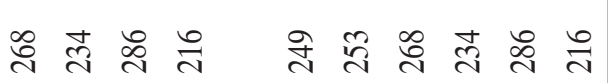

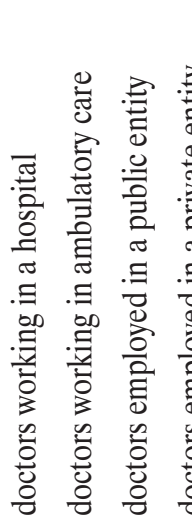

吕

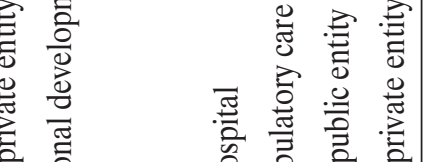

芯

寻 离

을 ڤ

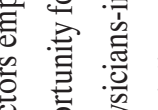

.

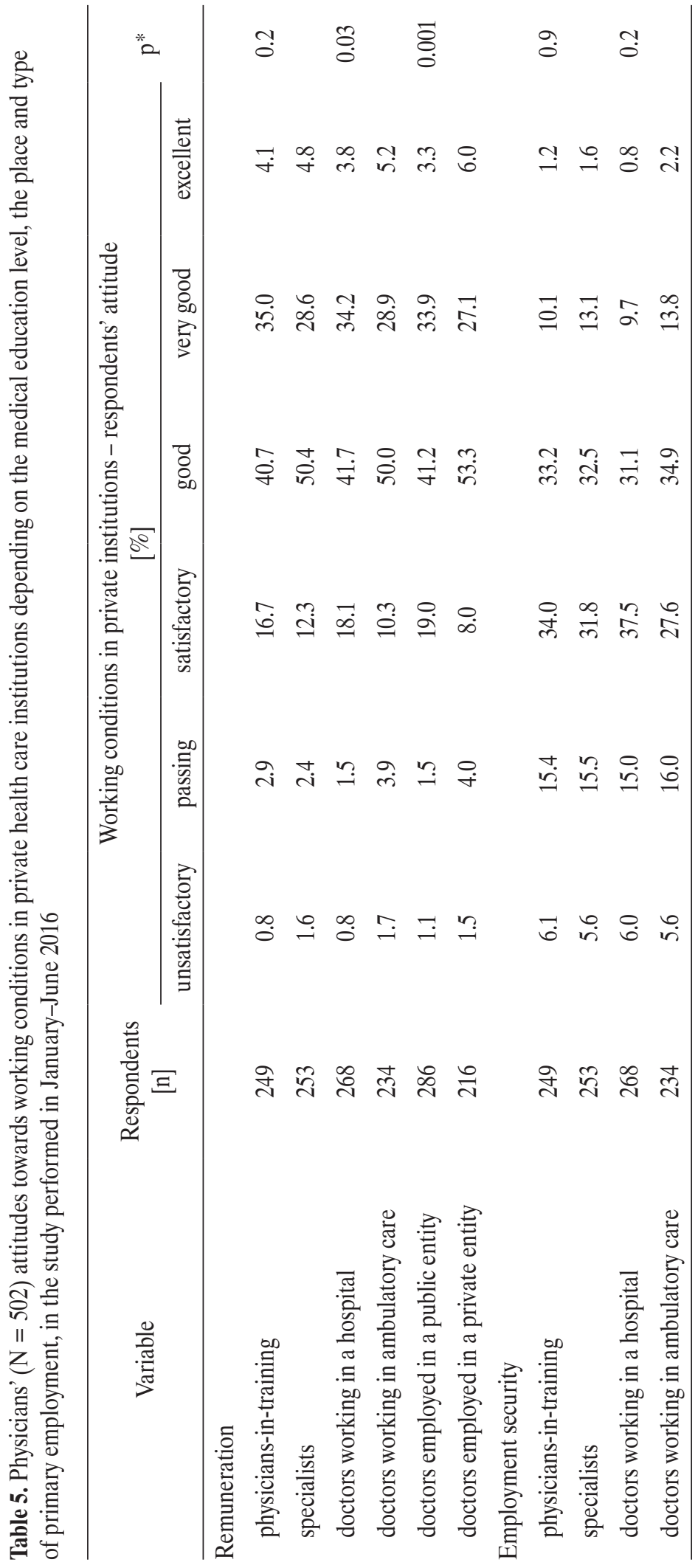

IJOMEH 2020;33(2) 


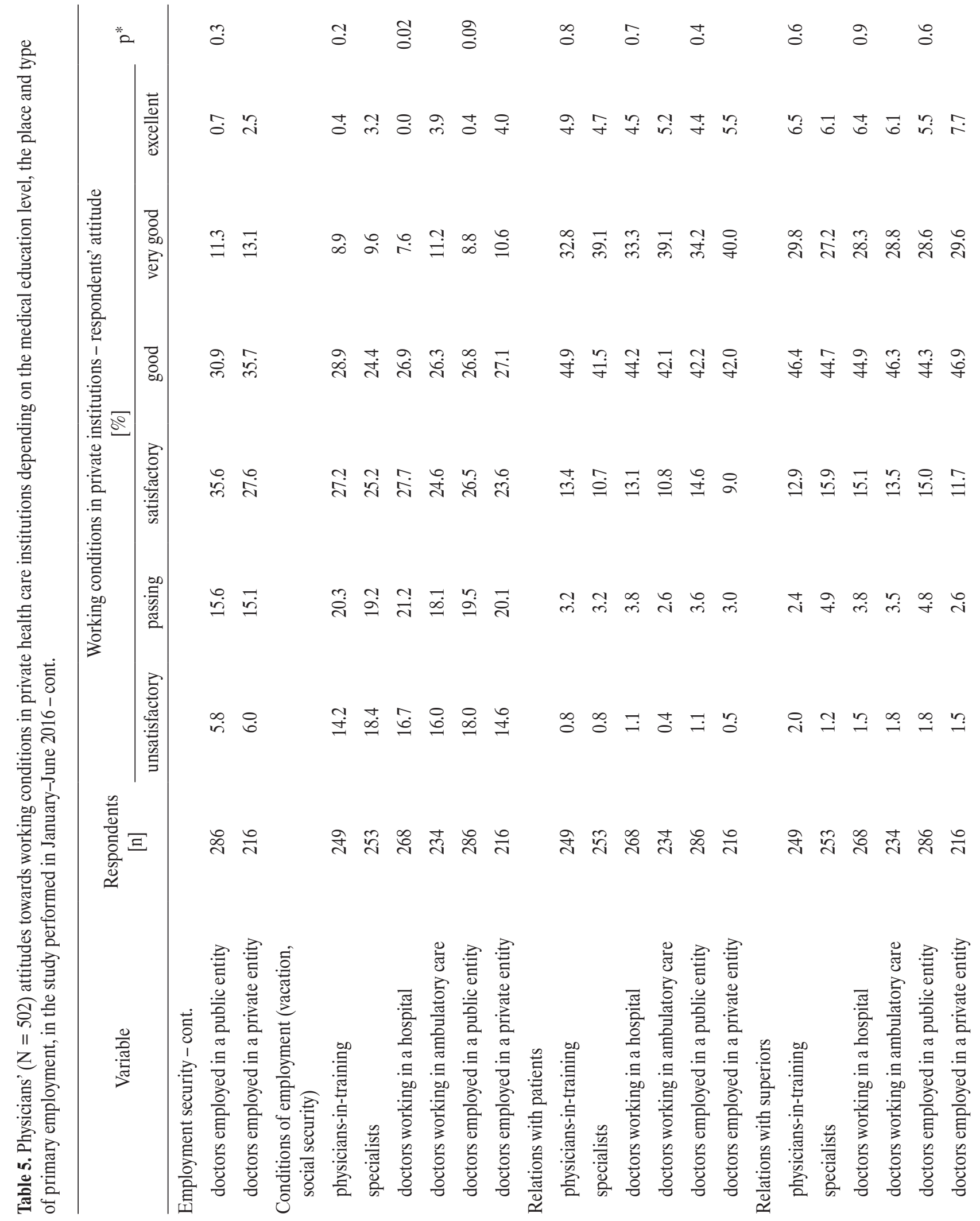




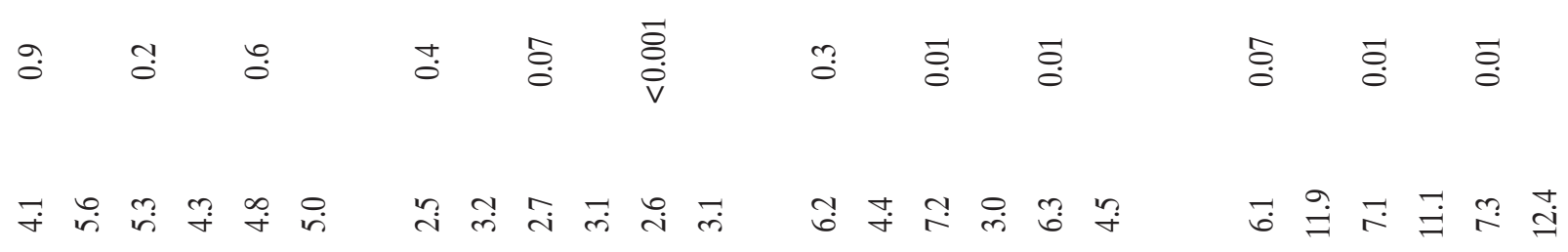

m

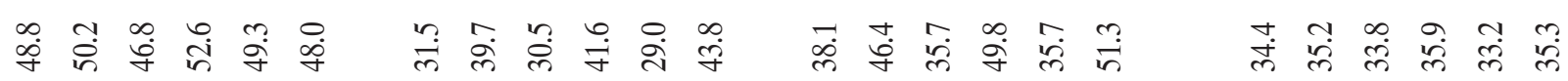

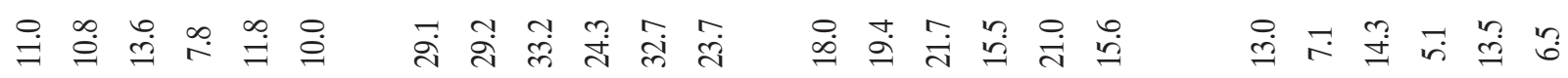

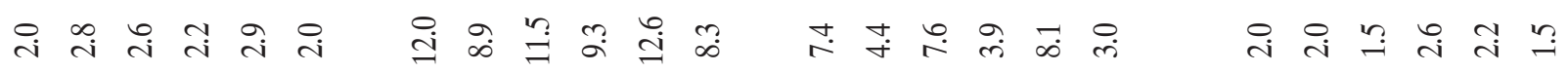

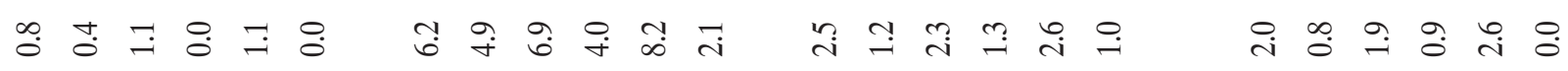

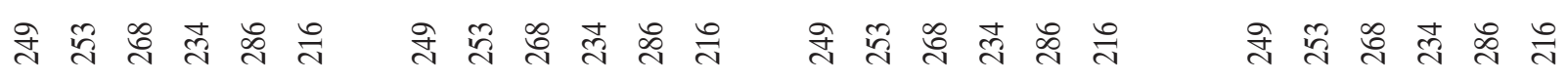

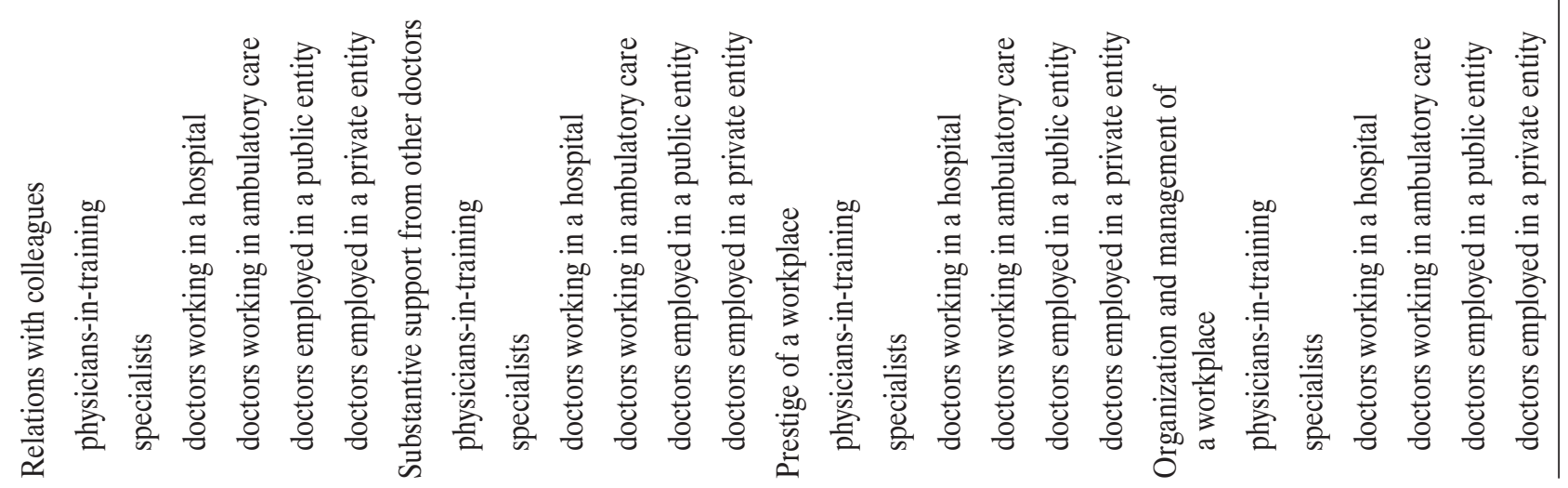




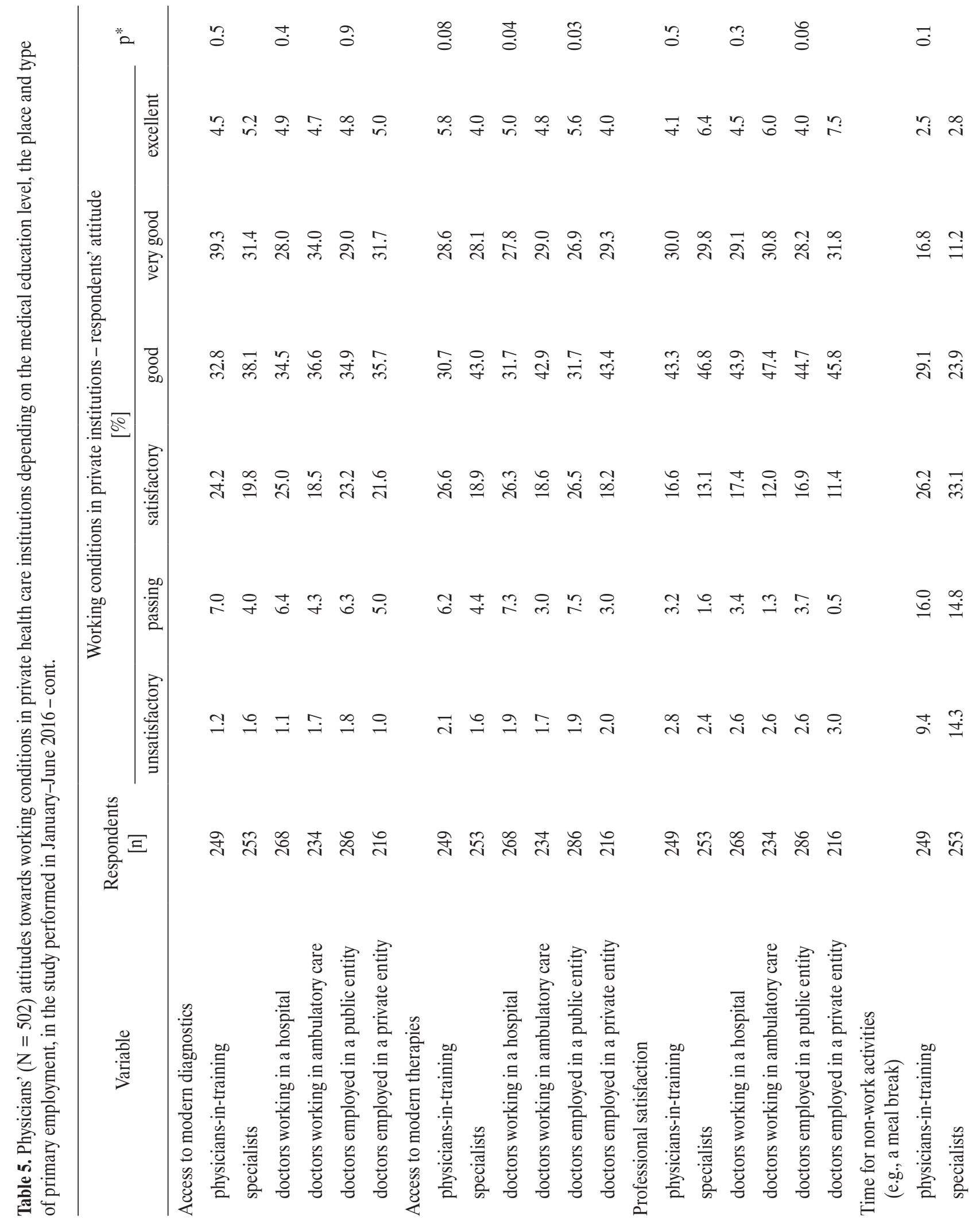




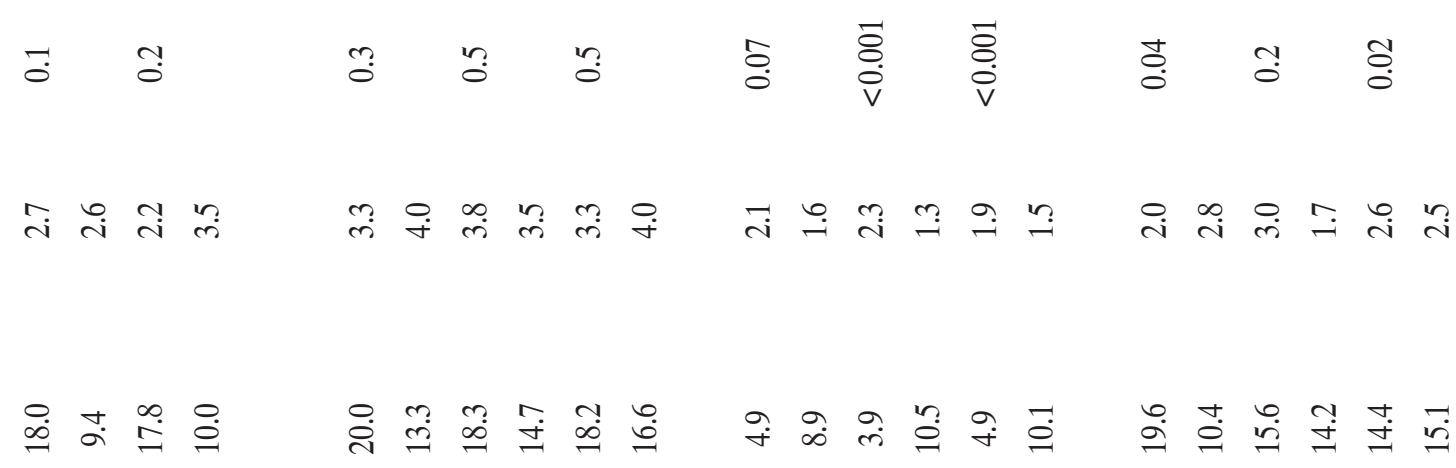

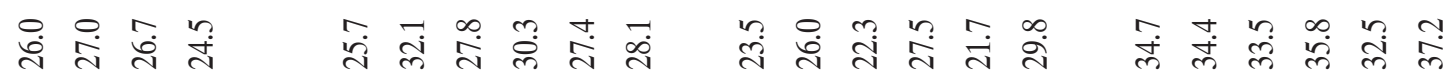

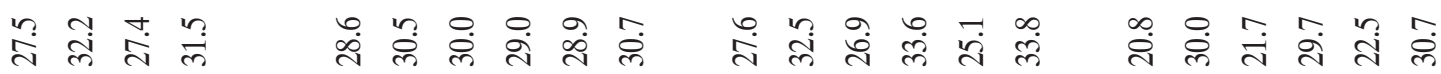

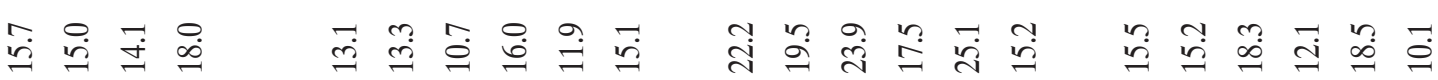

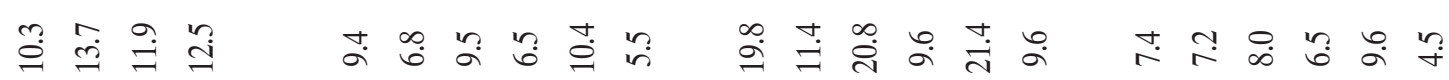

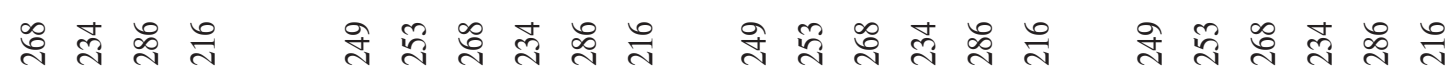

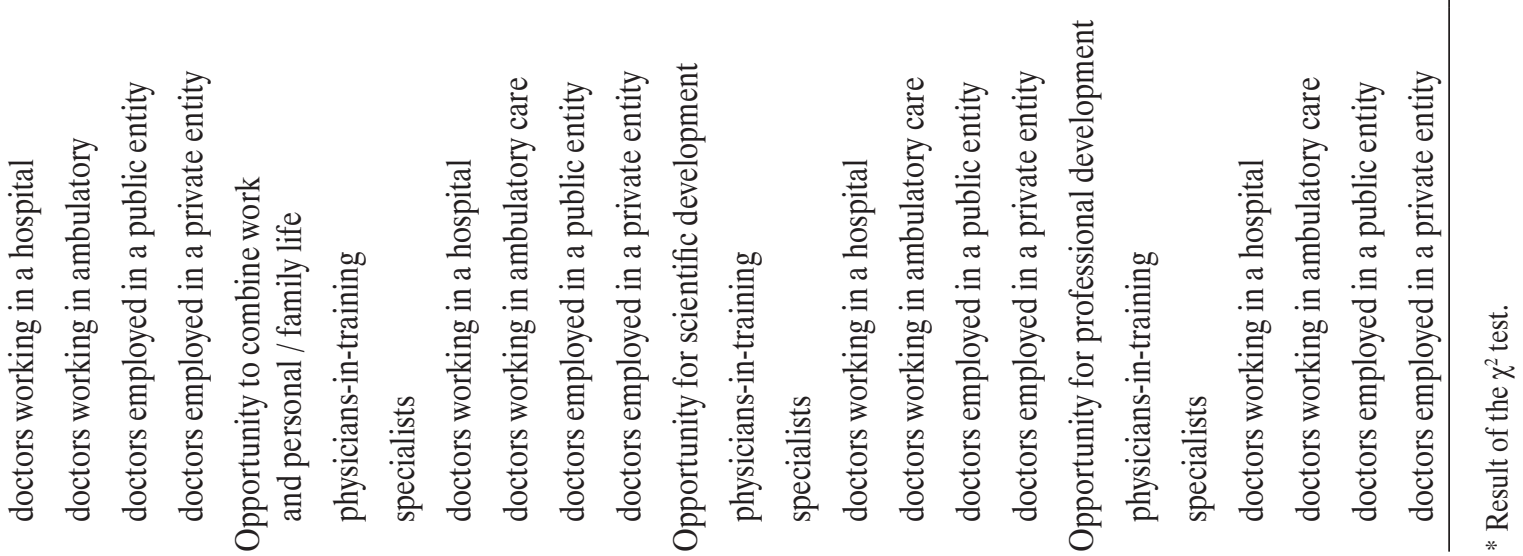




\section{DISCUSSION}

To the best of the authors' knowledge, this study is the first to assess and compare the attitudes towards the quality of services and working conditions in the public and private health care sector in Poland, from the physicians' perspective. According to the participating physicians, private medical facilities are better organized when compared to public units, which translates into the quality of medical services provided. In the opinions of the respondents, in both types of facilities, medical services are provided by competent medical staff, regardless of the ownership structure of the facility. Employment benefits and social security are perceived as the main advantages of practice in the public sector. On the other hand, employment in private entities is perceived as better paid and allowing for better relations with both patients and colleagues.

There is a shortage of health care professionals across the European Union, especially doctors and nurses $[13,14]$. More and more doctors choose to work in ambulatory care and move to the private health care sector [15]. The identification of differences between working conditions in the public and private sector helps in defining factors that are a priority when choosing a workplace. In this study, significant differences in attitudes towards working conditions in public and private health care entities were observed. The level of professional experience and the place where this experience was gained significantly shaped the attitudes of doctors towards working conditions in private and public health care entities. Perceived differences between working conditions in public and private institutions, as presented in this paper, can be an important guide for policy makers and health care managers, indicating what should be changed to encourage physicians to practice in the public health care sector.

In 2016-2018, the percentage of Poles who attended private medical services increased from $47 \%$ to $57 \%$ [8,9]. Threequarters of Poles chose private medical services due to shorter waiting times [9]. In this study, a short waiting time was the most often declared (88\%) advantage of private services, which is reflected in patients' opinions. Almost every fifth Pole chooses private health care due to the higher competences and involvement of doctors [8,9]. This was not reflected in the responses provided by the physicians participating in this study. In the opinion of most of the respondents, both public and private entities employ competent medical staff (70.5\%), highly involved (53.5\%) in patient care.

A study by Rybarczyk-Szwajkowska et al. [16] revealed that, in the opinion of managing boards of public health care entities in the Lódź Province, Poland, the competences and experience of medical staff play a crucial role in providing high-quality medical services. Krzton-Królewiecka et al. [17] assessed the perceptions of primary care from the perspective of general practitioners. The most positive opinion about the quality of primary care was declared by self-employed general practitioners working additionally in other facilities as well as employed in practices where students or residents are trained.

Maniluk et al. [12] measured customers' expectation and attitudes towards health care service quality in public and private ambulatory health care units operating in Poland. Patients consulting private services had higher expectations concerning medical equipment and infrastructure of the entity. Those who used public health care services expected better relations with medical staff. Different opinions are presented by physicians in this study. Only one-third of the participants indicated that private entities have better medical equipment, whereas nearly half of them (49\%) declared no differences between the infrastructure available in the public and private area. Moreover, the physicians rated significantly higher their relations with patients and colleagues when practicing in private services compared to public entities. However, in this study, most of the respondents declared that public health care should be provided by those entities which can guarantee high-quality services, regardless of the funding structure. 
The physicians' attitudes towards the quality of health care services differ between the countries. Tyssen et al. [18] compared the perceptions of physicians (nationwide, representative samples) practicing in Canada, Norway and the USA, concerning the national health care systems operating there [18]. The dominant part of physicians practicing in the USA (79\%) agreed that they could provide high-quality health care services, wherein this opinion was shared by $57 \%$ of Norwegian physicians and less than half (46\%) of Canadian doctors. In the study by Tyssen et al., $90 \%$ of physicians in Canada and Norway, and $84 \%$ of U.S. doctors, defined their level of job satisfaction as "at least somewhat satisfied" [18]. A cross-sectional survey performed by Domagała et al. among physicians working in Polish hospitals showed that the mean level of career satisfaction, evaluated using a 6-point scale, was $4.1 \pm 0.69$ pts [19]. In this study, the authors observed a significantly higher professional satisfaction level $(\mathrm{p}<0.001)$ among physicians working in the private area compared to the public one, which also varied between the surveyed doctors depending on the place and type of primary employment. However, employment in a public medical entity offered better opportunities for scientific and professional development.

This study has several limitations. Firstly, it was carried out among a selected group of physicians attending a course at the School of Public Health, the Centre of Postgraduate Medical Education in Warsaw, Poland. Nevertheless, the participation in the course is mandatory for each of 16200 physicians undergoing specialty training in Poland, and the study group represented different regions and health care institutions from all over the country. Moreover, this is the only available study comparing the attitudes towards public and private health care entities, from the point of view of physicians. Secondly, the physicians' beliefs and attitudes towards public and private health care services were based on responses from all the participants, regardless of their previous work experience in public or private health care institutions. Nevertheless, almost every doctor in Poland has some experience related to public health care (gained during undergraduate or postgraduate training), and the vast majority of physicians have worked at least once in private health care entities during their medical career. Moreover, the health care system in Poland is constantly changing. Data presented by the authors was collected in 2016. Since then, a number of reforms have been introduced, which can impact on the experience of working in the public or private services. Nevertheless, the Centre, as a reference unit responsible for postgraduate education of medical staff, carries out regular assessment surveys of the attitudes towards the health care system by physicians. Comparing data presented in this paper with preliminary data collected in 2018 from 98 respondents, the authors did not observe any significant differences $(p>0.05)$ in the distribution of responses to key questions that formed the basis of this paper.

\section{CONCLUSIONS}

In the opinion of physicians practicing in Poland, private medical entities are perceived as better organized and granting faster as well as more comprehensive access to health services when compared to public health care institutions. Opinions about working conditions in public and private entities differed between the surveyed doctors. Closing the gaps between working conditions in public and private units could encourage physicians to practice in the public health care sector. A regular monitoring of doctors' opinions about services quality and working conditions in private and public entities is necessary to address the needs of medical staff during the development of health care reforms.

\section{REFERENCES}

1. [The Constitution of the Republic of Poland of 2nd April, 1997. J Laws 78, item 483]. Polish.

2. Sagan A, Panteli D, Borkowski W, Dmowski M, Domanski F, Czyzewski M, et al. Poland health system review. Health Syst Transit. 2011;13(8):1-193. 
3. Zgliczyński WS. Healthcare system in Poland - selected issues. Studia BAS. 2018;(4):9-46, https://doi.org/10.31268/ StudiaBAS.2018.23.

4. National Health Fund [Internet]. Łódź: NFZ; 2015 [cited 2019 Apr 29]. Health Care in Poland. Available from: https://www.nfz-lodz.pl/index.php/dlapacjentow/leczenie-zagranica/98-leczenie-w-ue/279-health-care-in-poland. Polish.

5. Boulhol H, Sowa A, Golinowska S, Sicari P. Improving the HealthCare System in Poland. OECD Economics Department Working Papers, No. 957. Paris: OECD Publishing [cited 2019 Apr 29]. Available from: https://doi.org/10.1787/5k9b7bn5qzvd-en .

6. Polish Insurance Association. Annual report of the Polish Insurance Association for 2016 [Internet]. Warsaw: The Association; 2017 [cited 2019 Apr 28]. Available from: https:// piu.org.pl/wp-content/uploads/2016/11/PIU-Annual-Report-2016-in-PDF-version.pdf.

7. Polish Insurance Association. Report: "Financing the health care of employees" [Internet]. Warsaw: The Association; 2018 [cited 2019 Apr 28]. Available from: https://piu.org.pl/wpcontent/uploads/2019/04/Raport-zdrowotny-PIU.pdf. Polish.

8. Public Opinion Research Center. [Report: Using health care benefits and insurance 2016] [Internet]. Warsaw: CBOS Foundation; 2016 [cited 2019 Apr 29]. Available from: https://www.nil.org.pl/_data/assets/pdf_file/0006/108492/ CBOS-KOMUNIKATz-BADAn-NR-1122016-Korzystanieze-swiadczen-i-ubezpieczen-zdrowotnych.pdf. Polish.

9. Public Opinion Research Center (CBOS). [Report: Using health care benefits and insurance 2018] [Internet]. Warsaw: CBOS Foundation; 2018 [cited 2019 Apr 29]. Available from: https:// www.cbos.pl/SPISKOM.POL/2018/K_097_18.PDF. Polish.

10. Nieszporska S. Priorities in the Polish health care system. Eur J Health Econ. 2017;18(1):1-5, http://doi.org/10.1007/ s10198-016-0831-0.

11. Trastek VF, Hamilton NW, Niles EE. Leadership models in health care - a case for servant leadership. Mayo Clin Proc. 2014;89(3):374-81, https://doi.org/10.1016/j.mayocp.2013.10.012.
12. Manulik S, Rosińczuk J, Karniej P. Evaluation of health care service quality in Poland with the use of SERVQUAL method at the specialist ambulatory health care center. Patient Prefer Adherence. 2016;10:1435-42, https://doi.org/10.2147/ PPA.S108252.

13. Limb M. World will lack 18 million health workers by 2030 without adequate investment, warns UN. BMJ. 2016;354: i5169, https://doi.org/10.1136/bmj.i5169.

14. OECD/European Observatory on Health Systems and Policies. Poland: country health profile 2017, State of health in the EU [Internet]. Paris, Brussels: OECD Publishing; 2017 [cited 2019 Jul 09]. Available from: https://doi.org/10. 1787/9789264283510-en.

15. Deloitte [Internet]. New York: Deloitte, c.2017 [cited 2019 Jul 9]. Fera B. Outpatient services growth: Ambulatory physicians should be given greater independence Available from: https://blogs.deloitte.com/centerforhealthsolutions/ outpatient-services-growth-hospitals-consider-rewardingambulatory-physicians-independence/.

16. Rybarczyk-Szwajkowska A, Cichońska D, Holly R. [The way the quality of health services is perceived and treated by the managerial personnel of publichospitals]. MedPr.2016;67(3): 365-73, https://doi.org/10.13075/mp.5893.00233. Polish.

17. Krztoń-Królewiecka A, Oleszczyk M, Schäfer W, Boerma WG, Windak A. Quality of primary health care in Poland from the perspective of the physicians providing it. BMC Fam Pract. 2016;17(1):151, https://doi.org/10.1186/s12875-016-0550-8.

18. Tyssen R, Palmer KS, Solberg IB, Voltmer E, Frank E. Physicians' perceptions of quality of care, professional autonomy, and job satisfaction in Canada, Norway, and the United States. BMC Health Serv Res. 2013;13:516, https:// doi.org/10.1186/1472-6963-13-516.

19. Domagała A, Peña-Sánchez JN, Dubas-Jakóbczyk K. Satisfaction of Physicians Working in Polish Hospitals-A CrossSectional Study. Int J Environ Res Public Health. 2018; 15(12):E2640, https://doi.org/10.3390/ijerph15122640.

This work is available in Open Access model and licensed under a Creative Commons Attribution-NonCommercial 3.0 Poland License - http://creativecommons.org/ licenses/by-nc/3.0/pl/deed.en. 